\section{Environmental Chemistry in Society}

\author{
by James A.M. Beard: CRC Press, \\ Boca Raton, FL, USA, 2008, \\ ISBN: 978-1-4200-8025-4. \\ pp 364, Price: GBP 44.99, USD 69.95
}

On first opening this book it appeared to be a student and fairly low-level UScentric text describing the various levels of chemistry and physics involved in the environmental problems now prevalent around the globe. However on delving deeper it became clear that the author has researched the subject in depth, made the science relevant, easily understood and then integrated it to make a very coherent and quite enjoyable read. In typical student mode, each chapter ends with a series of questions with answers to be determined from the text.

By following the subject from prehuman occupation, though the Industrial Revolution, and into today, by using basic physico-chemical laws (e.g. the Law of Conservation leading into entropy and enthalpy), the origins and causes of today's problem are described - but as always the core of the problem is the profligate and wasteful use of the earth's resources.

Atomic theory, the Periodic Table, chemical symbols, chemical bonding, formulas, equations, acids, bases, oxidation and reduction are all introduced to explain the how, why and what of environmental contamination. Although organic chemical entities are restricted to the simpler compounds, the higher profile toxic agents (dioxins, pesticides, carcinogens) are structurally described together with how they are recycled by nature. Toxicology of both organic and inorganic compounds is given a complete chapter; how they are classified, metabolised, and interact, including their pathways of distribution within natural cycles and how they can be transmitted into humans.

The next third of the book concerns energy, with extensive descriptions of fossil fuels, their origins, geographical distribution, and advantages/disadvantages, alternative fuels and other "renewables" (biomass, solar, geothermal, hydrogen). Refreshingly the author adds a section on conservation within the home and personal transportation, remarking that the US consumes at least $40 \%$ more than it should through wasteful use, even adding a brief commentary on the development and advantages of electrically driven vehicles as replacements for the internal combustion engine.

The final chapters bring together the overall effects on the globe; the atmosphere, smog, acid rain; indoor pollution from biological contaminants and considerable detail on the more obviouscigarette smoking. There is one surprising statistic: $10 \%$ of lung cancer deaths in the US are attributed to radon penetration in the home.

Overall the data are well structured, plainly presented in a logical sequence with very few contaminating species left out. An excellent and thought-provoking presentation for students, and new graduates could also learn a great deal about their environment. 